\title{
Perfil do Turista com Base nos Elementos Astrológicos
}

\author{
Tourist Profile Based on Astrological Elements
}

Perfil del Turista Basado en Elementos Astrológicos

Bárbara Helenni Gebara Santin ${ }^{1}$

\begin{abstract}
Resumo
O presente artigo aborda o tema perfil do turista com o olhar da astrologia e, mais especificamente, dos elementos astrológicos. Encontram-se discussões sobre segmentação psicográfica, motivações e o comportamento do consumidor turista e sua personalidade de acordo com a parte da astrologia que influencia padrões básicos de percepção dos indivíduos: os elementos astrológicos Fogo, Terra, Ar e Água. O objetivo é analisar a possibilidade de a astrologia influenciar desejos, escolhas e/ou decisões relativos ao consumo consciente de atividades e serviços turísticos. Além disto, são apresentadas atividades turísticas que tem correspondência com as características de cada elemento astrológico. A pesquisa possui caráter exploratório e, a partir de aplicação de questionários e elaboração de mapas astrais, procura mostrar se as pessoas estão conscientes ou não de suas percepções de acordo com os elementos astrológicos que as influenciam de maneira dominante. Cada elemento astrológico possui um conjunto de características específico àquele elemento, dos quais dois dos quatro elementos exercem uma maior influência sobre o indivíduo (dominantes), enquanto os outros dois costumam agir inconscientemente. Os resultados da pesquisa apresentam relação com esta definição, onde a maioria dos entrevistados está consciente de dois ou um de seus elementos astrológicos dominantes. Esta consciência por parte dos próprios turistas pode possibilitar uma nova forma de olhar para o turismo.
\end{abstract}

Palavras-chave: Perfil do turista; Percepção; Personalidade; Astrologia.

\begin{abstract}
This article approaches the tourist profile subject with an astrological view and, more specifically, with the astrological elements view. There are discussions about psychographic segmentation, motivations and the tourist consumer behavior and his/her personality according to the side of astrology which influences basic patterns of perception of individuals: the astrological elements Fire, Earth, Air and Water. The goal is to analyze the possibility of astrology to influence desires, choices and/or decisions related to a conscious consumption of touristic activities and services. Additionally, tourist activities that correspond with each astrological element characteristics are presented. The research has an exploratory character and, through the questionnaires application and the preparation of the

\footnotetext{
${ }^{1}$ Mestranda em Geografia pelo Programa de Pós-graduação em Geografia da Universidade do Estado do Rio de Janeiro. Graduada em Turismo pela Universidade do Estado do Rio de Janeiro. Rio de Janeiro-RJ, Brasil. Email: barbarahelenni@gmail.com
} 
horoscope, searches if people are aware or not of their perceptions according to the astrological elements, those which influence them in a dominant way. Each astrological element has a group of specific characteristics to that element, where two of four elements exert a greater influence on the person, while the other two elements usually act unconsciously. The results of the research show relation with this definition, where the majority of the interviewed are conscious of two or one of their dominant astrological elements. This tourist's consciousness can present a new way to look to tourism.

Keywords: Tourist profile; Perception; Personality; Astrology.

\section{Resumen}

Este articulo aborda el tema perfil del turista con el aspecto de la astrología y, más específicamente, de los elementos astrológicos. Son encontradas discusiones acerca de segmentación psicográfica, motivaciones y el comportamiento del consumidor turista y su personalidad de acuerdo con la parte de la astrología que influye patrones básicos de percepción de los individuos: los elementos astrológicos Fuego, Tierra, Aire y Agua. El objetivo es analizar la posibilidad de la astrología influenciar deseos, preferencias y/o decisiones relativos a el consumo consciente de actividades y servicios turísticos. Además, son presentadas actividades turísticas que tienen correspondencia con las características de cada elemento astrológico. La investigación tiene carácter exploratorio y, a partir de la aplicación de cuestionarios y de la elaboración de mapas astrales, busca mostrar si las personas están conscientes o no de sus percepciones de acuerdo con los elementos astrológicos que las influencian de manera dominante. Cada elemento astrológico posee un conjunto de características específico aquel elemento, de los cuales dos de los cuatro elementos ejercen una influencia mayor sobre el individuo (dominantes), mientras los otros dos generalmente actúan inconscientemente. Los resultados de la investigación presentan relación con esta definición, donde la mayoría de los entrevistados está consciente de dos o un de sus elementos astrológicos dominantes. Esta consciencia por parte de los propios turistas puede posibilitar una nueva forma de mirar para el turismo.

Palabras claves: Perfil del Turista; Percepción; Personalidad; Astrología.

\section{Introdução}

A atividade turística se trata de pessoas e, do lado mercadológico, se trata de saber receber, guiar, satisfazer desejos e até mesmo necessidades. Necessidades e desejos de pessoas que possuem gostos, vontades, interpretações, maneiras de observar e perceber diferentes. Turismo para elas pode representar uma forma de libertação, lazer, relaxamento, conhecimento, aprendizagem e até mesmo salvação. Uma viagem pode mudar a vida de um indivíduo, mudar olhares, mentes e hábitos (ATELJEVIC, 2011; BENI, 2008). Com esta visão, diferentes intenções e percepções de um indivíduo relativas à realização de uma viagem podem ser interpretadas através da astrologia. 
O objetivo do presente artigo é relacionar as percepções dos turistas com os elementos astrológicos Fogo, Terra, Ar e Água. Estes perfis têm base na astrologia, um instrumento de autoconhecimento e que, neste caso, pode fornecer informações sobre a personalidade, os gostos, os desejos e as motivações do turista. Ou seja, podemos saber que tipos de atividade e experiências turísticas possuem maior chance de satisfazer esses perfis básicos.

Foi realizada uma pesquisa bibliográfica para embasar o assunto a partir de áreas como a astrologia, a psicologia, a sociologia, a antropologia, a geografia e a economia, já que o foco principal do estudo é o indivíduo turista. Para a elaboração de atividades turísticas relacionadas aos elementos astrológicos foram utilizadas bibliografias que descrevessem estas atividades e, nelas são apresentadas as relações das atividades com os padrões energéticos de cada elemento. Para a pesquisa empírica foi elaborado e aplicado um questionário sobre personalidade, o qual está relacionado com os elementos astrológicos (sem que os entrevistados tivessem conhecimento dos mesmos, somente de suas características).

Este artigo trará foco para os níveis básicos de percepção e energia do indivíduo para uma compreensão um pouco mais pessoal do comportamento do turista e seus gostos. Estes níveis básicos de percepção são explicitados, neste caso, pelos elementos astrológicos Fogo, Terra, Ar e Água. Cada um deles apresenta um conjunto de características relacionadas à personalidade e ao modo de enxergar o mundo de um indivíduo.

Além da introdução e conclusão, este trabalho está estruturado em seis seções. A primeira seção fala de uma maneira geral sobre turismo e turista. A segunda seção aborda o comportamento do turista, experiências turísticas, as tendências de comportamento e de necessidades ligadas ao lazer. A terceira seção apresenta um marco teórico sobre a astrologia, mapa natal e elementos astrológicos. A quarta une turismo e astrologia para identificar atividades turísticas correspondentes às percepções do turista com base nos quatro elementos astrológicos. A quinta apresenta a metodologia de pesquisa utilizada para identificar indivíduos que estão cientes ou não de seu tipo básico de percepção. E a última seção referese à análise dos resultados da pesquisa.

\section{Materiais e Métodos}

A metodologia de pesquisa utilizada para este artigo tem caráter exploratório. Trata-se de uma pesquisa teórica, descritiva e empírica de cunho qualitativo e quantitativo (DENCKER, 1998; 
MARCONI; LAKATOS, 2002; MOESCH, 2002; VEAL, 2011). Na primeira parte da pesquisa foi realizado um levantamento bibliográfico sobre comportamento do turista e astrologia a fim de criar uma base para a pesquisa empírica.

\subsection{Turismo e comportamento do turista: do consumo à segmentação psicográfica}

Com o apoio da psicologia é possível ter acesso aos desejos dos turistas e conhecer, ao menos de forma básica, o que motiva cada um e quais são suas percepções nas viagens (BACAL, 2003; JENKINS, 1999; MANOSSO et al, 2012; SWARBROOKE; HORNER, 2002). A importância deste tipo de estudo é ressaltar o fato de que cada ser humano é diferente e possui maneiras de olhar, de pensar e de sentir diferentes. É isso que é preciso alcançar para que sejam obtidos outros resultados de turismo, com mais consciência, onde a realização de uma viagem possa dar a possibilidade de o indivíduo se autoconhecer e se satisfazer.

A nossa atual cultura vê nas viagens possibilidade de viver experiências de conexões com algo maior, isto faz com que a promoção do turismo seja um indutor das motivações conscientes e também inconscientes das pessoas. Com este evento supõe-se que o desejo está conectado com aspectos profundos da mente humana (BACAL, 2003). Com esta conexão com os desejos, o turista entra em contato consigo. Então a atividade turística também é uma propulsora para os questionamentos humanos e para o autoconhecimento.

Em relação ao autoconhecimento e, consequentemente, à personalidade, existem elementos como consciente, o qual representa a racionalidade e o autoconhecimento do indivíduo; inconsciente, conhecimentos psíquicos não disponíveis à consciência; percepção, que é o conhecimento através da sensação das formas, para as quais são dados sentido e significado; e imaginação, a qual dá acesso a possibilidades e ao que pode estar profundo dentro do indivíduo (CHAUI, 2010).

Para Krippendorf (2009), um turismo baseado no ser humano e suas percepções é criado a partir da viagem consciente e dá a chance de o turista explorar a potencialidade do que ele é, isto é educação para a viagem. Krippendorf (2000 apud FONSECA FILHO, 2007, p. 16) ainda destaca: "por meio dessa educação para a viagem o turista terá contato com sua personalidade." A partir disto o turismo pode dar em troca para o experimentador momentos, sensações, sentimentos, pensamentos e conexões. Neste sentido, Baudrillard (1993 apud MELO, 2009, p. 86) diz que "os objetos nunca são consumidos em si, isto é, pelo seu valor de uso, mas sim como signos que se inter-relacionam, formando um sistema complexo de significação e comunicação”. 
A satisfação do turista está diretamente ligada com as experiências que ele vive no destino e com a imagem que ele tem do local (CHON, 1992; PINTO, 2012), ou seja, está diretamente ligada aos impactos positivos que a experiência - e sua relação com o que ele espera oferece, e o que pode agradar e satisfaze-lo é a realização de seus desejos, os quais são intrínsecos à sua personalidade. Como diz Lemos (2005 apud TONINI, 2009, p. 93), “o turismo não lida apenas com necessidades, mas também com desejos e sonhos; busca o suprimento das necessidades materiais e, além destas, das subjetivas”.

A viagem pode ser um recomeço, o início de um novo olhar perante a vida e a si mesmo. Krippendorf (2009) novamente complementa:

É bem conhecido o fato de que é precisamente num ambiente incomum e estranho que retomamos a consciência da nossa própria realidade. Segundo essa tese, a viagem proporciona-nos a possibilidade de descobrirmos o caminho que nos conduz a nós mesmos. Temos tempo para ocupar-nos com o nosso próprio eu, para explorar a própria alma, para redescobrir a harmonia interior, para compararmo-nos ao outro e descobrir nossas aptidões (p. 48).

Algumas motivações pesam mais para um turista que para outro, o imaginário turístico possui natureza subjetiva (BIGNÉ et al., 2001; DOLNICAR; HUYBERS, 2007; JENKINS, 1999), por isso há impressões diferentes (ECHTNER; RITCHIE, 1991; MILMAN; PIZAM, 1995) e percepções diferentes (COSHALL, 2000; TAPACHAI; WARYSZAK, 2000). Com isto, a reflexão sobre o sentido da vida tem se tornado mais forte na sociedade atual (ATELJEVIC, 2011; ELGIN, 1997; INGLEHART, 1977; INGLEHART; NORRIS, 2004).

A experiência - e a qualidade da mesma - vivida pelo turista em uma atividade turística ou destino é o componente mais importante de toda a viagem. Segundo Gândara et al. (2009, p. 187), “o turista contemporâneo deseja deslocar-se para destinos onde possa mais que contemplar, viver e emocionar-se, ser o personagem da sua própria viagem. Ele anseia envolver-se nas experiências". Ainda segundo Manosso et al: (2012)

Percebe-se a complexidade na mensuração das emoções, causando assim, algumas restrições, devido, principalmente seu caráter de inconstância, ou seja, as emoções podem ser as mesmas, mas o modo como a mesma é 'sentida' pelas pessoas é diferente, e as situações nas quais elas são suscitadas também (p. 371). 
Rudhyar (1972) diz que a experiência é percebida através da consciência e da respectiva relação que é feita das experiências atuais com as experiências passadas, as quais podem ser individuais ou coletivas. Rudhyar (1972) ainda diz que:

Se houver consciência de modificações internas e externas haverá experiência; mas essa experiência é, quase sempre, em parte condicionada por fatores biológicos externos, em parte por pressões intelectuais e emocionais da família, da cultura e da sociedade. Quando isso ocorre, a experiência não é 'pura' em termos da individualidade essencial da pessoa. O que nosso atual 'treinamento da sensibilidade' [...] procura produzir é uma purificação de experiências individuais (p. 44).

A experiência vivida a partir da percepção individual e pura possibilita que o turista tenha um contato ou uma ligação intensa com o ambiente e consigo. Para ter acesso ao estudo da satisfação de acordo com a personalidade, a segmentação psicográfica é um meio de encontrar uma teoria que aborde tal conteúdo, ela é "a técnica ou a ferramenta que permite a mensuração quantitativa dos estilos de vida, englobando personalidades, valores, atividades, interesses e características demográficas" (FINOTTI, 2002 apud LOHMANN; NETTO, 2008). A segmentação psicográfica também é importante porque ela "parte da ideia de que o estilo de vida, as atitudes, opiniões e a personalidade das pessoas determinam o seu comportamento enquanto consumidores" (SWARBROOKE; HORNER, 2002, p. 139).

A imagem e a percepção - de um destino, por exemplo - terão diversas variações dependendo do turista (BALOGLU; MCCLEARY, 1999; BEERLI; MARTÍN, 2004; BOSQUE; MARTÍN, 2008; ECHTNER; RITCHIE, 1991; GALLARZA et al., 2002; GUITIÉRREZ, 2005). Essa imagem será um propulsor importante da motivação da viagem.

Em outra importante abordagem, o sistema cultural no qual vivemos nos apresenta um conjunto de simbologias e imagens que possuem ligação com o cotidiano e com o imaginário, os quais funcionam como projeções que estão ali para que nos identifiquemos com elas (MORIN, 1975). Porém existe um querer e uma motivação que não depende do que nos é apresentado e do que é imposto pela sociedade. Este querer vem de cada indivíduo, vem da personalidade e do imaginário de cada um.

Esta motivação, quando relacionada diretamente com o desejo do indivíduo, está atrelada à sua personalidade. E para analisar a personalidade de cada indivíduo a astrologia é um instrumento de autoconhecimento que pode ser utilizado. Assim é importante lembrar que os seres humanos estão conscientes apenas de uma parte da personalidade e de todas as 
possibilidades de ser quem são. Muito do que são está inconsciente, ou muitas vezes, em forma de incerteza. No consciente há a percepção clara de pensamentos, sensações, sentimentos e lembranças; no inconsciente existem sentimentos e desejos que não estão disponíveis ao consciente (FREUD, 1974; VIEIRA FILHO, 2014).

Sabendo que existem recursos inconscientes e muitas vezes fora do alcance do ser humano, é necessário ter o seguinte pensamento, segundo Lamm (1987), em mente:

Precisamos reafirmar a existência e o valor do espírito... nossa sociedade [precisa] aprender que existe uma sabedoria maior à espera da nossa paciente investigação; que o homem é um animal espiritual, bem como bioquímico, psicológico, político, social, legal e econômico (apud ARROYO, 1989, p. 20).

Na segunda seção será apresentada a teoria astrológica e como ela é incluída na busca de plenitude e/ou satisfação nas viagens, assim como sua relação com a personalidade e a percepção do turista.

\subsection{Astrologia e suas aplicações}

A astrologia deve ser direcionada para a qualidade do pensar, do agir e do sentir. Uma experiência humana é analisada a partir da qualidade desses fenômenos e não dos fenômenos em si. É esta qualidade que motiva o indivíduo, mesmo que esta motivação esteja inconsciente (RUDHYAR, 1972). Em relação à reconexão com a consciência astrológica, Arroyo (1989) diz:

Ao colocar o ser humano num quadro de referência cósmico, a astrologia, e somente ela, tem a capacidade de resintonizar a consciência de uma pessoa com sua natureza essencial e de estimular um profundo nível de autoconhecimento. [...] Se a astrologia for corretamente utilizada, não é preciso sobrepor a ela uma linguagem ou uma teoria complexa; ela pode ser apenas uma simples explicação dos fatores cósmicos e das energias vitais que operam dentro da pessoa e por meio dela (p. 27).

A astrologia se baseia nos movimentos dos astros em relação à Terra e às energias que são captadas pelos seres que vivem neste planeta. Os astros são representados pelos luminares e planetas e o zodíaco é a estrutura por onde eles se expressam. O zodíaco é dividido em doze partes correspondentes aos doze signos. Estas partes são a base do mapa astrológico, o instrumento utilizado para indicar a personalidade e as potencialidades de um indivíduo.

Mapa astrológico ou mapa natal é o conjunto de possibilidades de ser de uma pessoa. Nele estão presentes todas as características e informações referentes à personalidade, à percepção, às motivações, aos medos, aos desejos, aos obstáculos etc. Segundo Rudhyar (1972), 
O mapa astrológico é encarado como a fórmula estruturalmente definidora da 'natureza fundamental' de uma pessoa. É um complexo símbolo cósmico - uma palavra ou logos revelador do que a pessoa potencialmente é. É o 'nome celeste' de uma pessoa e também um conjunto de instruções sobre como ela pode realizar melhor aquilo que por ocasião de seu nascimento era potencial puro - 'potencialidade germinal'. O mapa astrológico é [...] um meio para alcançar uma integração todo-abrangente da personalidade (p. 27).

De acordo com Banzhaf e Haebler (1994, p. 10) "No mapa astrológico expressa-se a interação entre três níveis de efeitos. São eles os planetas nos signos, os planetas nas casas e os aspectos entre os planetas". Existe também a influência dos elementos, os quais possuem conjuntos de características. Os elementos se destacam através dos signos do zodíaco e das casas astrológicas do mapa natal (HAMAKER-ZONDAG, 1989). Os elementos são Fogo, Terra, Ar e Água. No zodíaco eles ditam os padrões de comportamento ligados à energia e consciência do indivíduo.

Seguindo com este raciocínio, a localização dos planetas nos signos e nas casas pode dizer muito a respeito do tipo de energia que tem maior domínio sobre o indivíduo, já que os signos e as casas manifestam as energias dos elementos (HAMAKER-ZONDAG, 1989; RUDHYAR, 1972).

Então o mapa natal é estruturado em signos do zodíaco e casas astrológicas (conforme Figura 1), os planetas se localizam nesta estrutura do mapa. Na Figura 1 os signos do zodíaco são representados pelos símbolos da roda externa (azul) e as casas são as doze divisões de espaço mais ou menos iguais na parte mediana da roda.

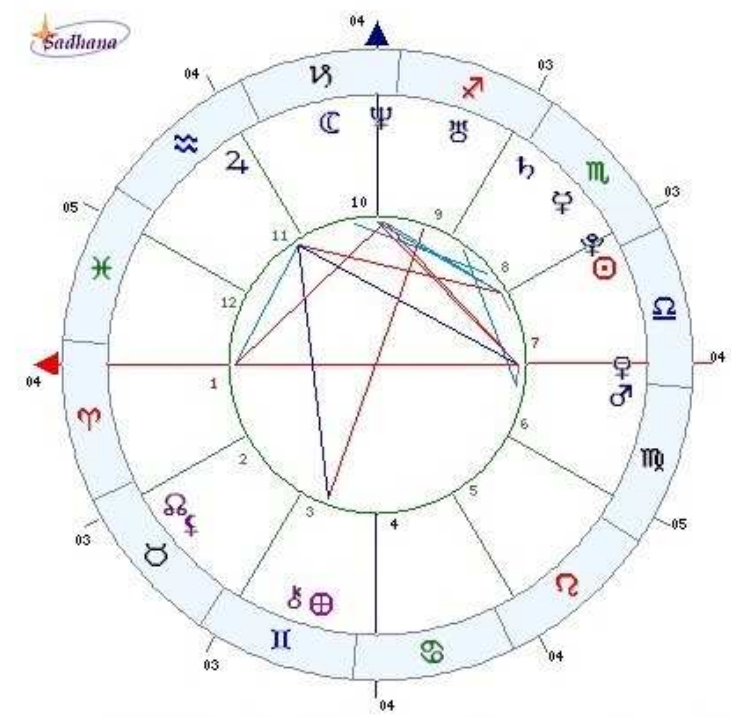

Figura 1- Mapa Astrológico ou Mapa Natal

Fonte: www.sadhana.com.br, 2014. 
Os planetas e luminares são representados pelos símbolos localizados nas casas. Segundo Arroyo (1989),

O mapa astrológico natal é traçado para o momento da primeira respiração, aquele instante em que estabelecemos imediatamente, e para toda a vida, a nossa sintonia com as fontes de energia cósmica. O mapa natal, portanto, revela seu padrão de energia, ou a sua sintonia cósmica com os quatro elementos. Em outras palavras, o mapa simboliza o padrão das várias manifestações vibratórias de que se compõe a expressão individual neste plano da criação (p. 39).

De acordo com Arroyo, (1989), Hamaker-Zondag, (1989), Lundsted (1989) e Rudhyar (1989) existe um método de análise baseado nos elementos astrológicos que pode indicar a maneira como o indivíduo percebe as coisas ao seu redor e é um grande diferencial para a identificação das motivações do turista.

$\mathrm{Na}$ astrologia e em relação ao ser humano, os elementos determinam o modo de ver e perceber objetos, fenômenos, situações etc. e são a primeira parte de diferenciação ou individuação do ser humano (ARROYO, 1987; HAMAKER-ZONDAG, 1989) e, de acordo com Lundsted (1989),

A divisão [...] Fogo - Terra - Ar - Água no horóscopo pessoal pode dar um insight nos impulsos e necessidades individuais. Esses [...] elementos indicam, num nível [...] básico, qual é o fluxo de energia natural do indivíduo e o que esta pessoa está buscando em sua vida (p. 69).

De modo consciente, algumas pessoas se identificam ou se sintonizam mais com certos tipos de energia, ou seja, de elementos do que outras (ARROYO, 1989). Dentre esses quatro tipos básicos de energia, existem dois com os quais estamos mais conscientemente conectados (HAMAKER-ZONDAG, 1989; LIMA, 1998).

Segundo a autora Karen Hamaker-Zondag (1989), existe uma maneira de calcular os elementos mais presentes no comportamento consciente de um indivíduo. Este cálculo é feito a partir dos planetas, luminares (Sol e Lua), ascendente e meio do céu e são suas respectivas localizações nos signos do zodíaco e nas casas astrológicas do mapa natal que indicam a maior ou menor absorção da energia de cada elemento. Verificam-se primeiramente os planetas presentes nos signos e seus respectivos elementos, depois identificam-se os planetas presentes nas casas astrológicas e também seus respectivos elementos. Utilizando o mapa 
natal da Figura 1 como exemplo, a contagem dos elementos - através da localização dos planetas - funciona da seguinte maneira (Quadro1):

Quadro 1- Soma da quantidade de cada elemento astrológico presente no mapa natal

\begin{tabular}{|c|c|c|c|}
\hline Elementos astrológicos & Signos do zodíaco & Casas astrológicas & Total \\
\hline Fogo & Ascendente e Urano & Urano & 3 \\
\hline Terra & Meio do céu, Lua, Marte e Netuno & Lua, Marte e Netuno & 7 \\
\hline Ar & Sol, Vênus e Júpiter & Sol, Vênus e Júpiter & 6 \\
\hline Água & Mercúrio, Saturno e Plutão & Mercúrio, Saturno e Plutão & 6 \\
\hline
\end{tabular}

Fonte: Adaptado de Hamaker-Zondag (1989).

O que é considerado no momento de verificar a localização dos planetas e luminares nos signos e nas casas não é o signo do zodíaco em si e nem o signo correspondente à casa astrológica, mas sim o elemento astrológico relativo ao signo e à casa.

$\mathrm{Na}$ segunda coluna do quadro 2 foram observados os planetas e luminares presentes nos signos do zodíaco, ao mesmo passo que foram observados os elementos destes signos. Então foi verificado, no mapa natal da figura 1, que o Ascendente e Urano se encontram em signos do elemento Fogo (Áries e Sagitário respectivamente); o Meio do céu, Lua, Marte e Netuno se encontram em signos do elemento Terra (Capricórnio e Virgem); Sol, Vênus e Júpiter se encontram em signos do elemento Ar (Libra e Aquário); e Mercúrio, Saturno e Plutão encontram-se em signos do elemento Água (Escorpião).

$\mathrm{Na}$ terceira coluna foram observados os planetas e luminares presentes nas casas astrológicas, ao mesmo tempo em que seus elementos correspondentes também foram observados. Foi verificado então que Urano está localizado em uma casa de Fogo (casa 9); Lua, Marte e Netuno estão localizados em casas de Terra (casas 6 e 10); Sol, Vênus e Júpiter estão presentes em casas de Ar (casas 7 e 11); e Mercúrio, Saturno e Plutão estão presentes em uma casa de Água (casa 8).

No mapa natal da figura 1 o primeiro elemento dominante é Terra (com somatório de sete pontos), pois foi o elemento com maior número de planetas, luminares, ascendente e/ou meio do céu localizados nele. O segundo elemento dominante é Ar (com somatório de seis pontos). O segundo elemento dominante é Ar, e não Água, porque o que determina um elemento dominante em caso de empate é o Sol, como Hamaker-Zondag (1989, p. 24) mesmo diz: "o Sol desempenha um papel especial em qualquer conclusão sobre os elementos.”; isto porque 
ele "representa o espírito, ou o verdadeiro self." (LUNDSTED, 1989, p. 57). Na figura 1 o Sol está posicionado em signo e casa de elemento Ar.

De acordo com Arroyo (1987), Hamaker-Zondag (1989), Banzhaf e Haebler (1994) e Lima (1998), Fogo representa dinamismo, espontaneidade, intuição, expressão, expansividade, impulsividade, entusiasmo, vitalidade, criatividade, generosidade e busca de sentido; Terra representa realidade, concretude, matéria, sensação, beleza, praticidade, cautela, segurança, paciência, disciplina, determinação, responsabilidade e realização; Ar representa pensamento, ideias, teorias, comunicação, sociabilidade, flexibilidade, originalidade, curiosidade, diversidade, harmonia, conhecimento e equilíbrio; Água representa sentimento, emoção, sensibilidade, compaixão, imaginação, subjetividade, solicitude, profundidade, confiança e união.

Estas características podem ser perceptíveis pelas próprias pessoas e pelos outros e também referentes a atividades externas (BANZHAF; HAEBLER, 1994; HAMAKER-ZONDAG, 1989), como as atividades turísticas. Na próxima seção os temas turismo e astrologia serão ligados, assim como as percepções do turista e as atividades turísticas correspondentes com os tipos de percepções, ambos baseados nos elementos astrológicos.

\subsection{Turismo e astrologia}

A astrologia já foi assunto abordado e pesquisado na área do marketing. Gulmez, et al. (2011), Mitchell (1995) e Mitchell e Haggett (1997) são autores que pesquisaram a influência da astrologia no comportamento do consumidor. Este conhecimento já é utilizado no mundo dos negócios como cita Mitchell (1995):

A astrologia entrou também no mundo dos negócios. Já em 1973, Herzberg
registrou que os astrólogos foram consultados sobre problemas como locais
de plantas, recrutamento e mudanças no mercado. Ele relatou entrevistas
com dois consultores astrológicos. A primeira, Katina Theodossiou, disse
que ela tem 52 clientes corporativos na Europa e nos EUA. O segundo, Hans
Genuit, afirmou que ele aconselhou mais de 80 empresas em 28 países.
Herzberg sugeriu que uma das razões para esse interesse em astrologia era
que "todos nós temos a sensação subjetiva que existem coisas não
probabilísticas acontecendo. A astrologia ajuda psicologicamente as pessoas
a impor um padrão nisso (1973, p. 37$)$ " (p. 49).

Também é possível que a astrologia se encaixe nas tendências que surgem nos dias atuais sobre a prática do turismo relacionada à máxima satisfação do turista e sobre como o mercado 
pode satisfazê-los e atender a desejos específicos e ainda, saber conduzir e direcionar esses desejos para que haja satisfação. E em se tratando de como isto seria possível, Gulmez et al. (2011) se prontificam:

Os comerciantes devem saber quem o consumidor é e quais são os fatores internos e externos que criam os consumidores. Isso porque o consumidor toma a decisão de compra em relação à pressão desses fatores. [...] Em geral, os fatores psicológicos ou internos são personalidade, percepção, atitude e motivação (p. 97).

E Cohen (1972) finaliza:

Não existe o turista enquanto tal, mas uma variedade de tipos de turistas ou modos da experiência turística. [...] Aquilo que ele denomina o 'experiencial', o 'experimental' e o 'existencial' não se apoia na bolha ambiental dos serviços turísticos convencionais (apud URRY, 1996, p. 24).

Precisa-se pensar no indivíduo se quisermos que o turismo seja uma atividade consciente. Precisase de serviços que atendam e ofereçam atenção e cuidado relativos à personalidade do turista.

Os elementos astrológicos são imprescindíveis para se ter uma noção de como o ser humano percebe os objetos e fenômenos a sua volta, por isso eles foram escolhidos para a elaboração dos perfis do turista. Serão apresentadas atividades turísticas que podem corresponder às características dos quatro elementos astrológicos. Foi analisada a energia de cada elemento e as energias que as atividades podem proporcionar. Foi feita uma relação entre as formas de percepção do turista com base nos elementos astrológicos, apresentadas anteriormente, e as atividades turísticas que potencialmente proporcionam as energias e sensações semelhantes ao conceito de cada elemento astrológico (Quadro 2).

Quadro 2 - Os elementos astrológicos e as respectivas atividades turísticas

\begin{tabular}{|c|l|}
\hline $\begin{array}{c}\text { Elemento } \\
\text { astrológico }\end{array}$ & \multicolumn{1}{|c|}{ Atividade turística } \\
\hline Fogo & $\begin{array}{l}\text { Atividades que agucem o dinamismo, a espontaneidade, a impulsividade, a intuição e a conexão } \\
\text { com o algo maior e consigo mesmo, como Turismo de aventura, trilhas, atividades } \\
\text { exploratórias, visitas a templos e lugares sagrados, atividades radicais principalmente em } \\
\text { ambientes como floresta, montanha, cachoeira, praia etc. }\end{array}$ \\
\hline Terra & $\begin{array}{l}\text { Atividades que valorizem os sentidos físicos, a atitude realista e prática. Gastronomia local, } \\
\text { Turismo rural - pelo contato com a terra }-, \text { visita a museus e exposições de arte, hospedagem } \\
\text { em Spas. }\end{array}$ \\
\hline Ar & $\begin{array}{l}\text { Atividades que instiguem as sinapses, a comunicação, a sociabilidade e a flexibilidade, como o } \\
\text { Turismo de estudos, intercâmbios culturais, Turismo social, contato com os moradores do local. }\end{array}$ \\
\hline Água & $\begin{array}{l}\text { Atividades que valorizem a sensibilidade, a imaginação e o contato com os sentimentos, como } \\
\text { apresentações musicais e expressões artísticas no geral, Turismo exotérico, Turismo religioso. }\end{array}$ \\
\hline
\end{tabular}

Fonte: Elaboração do autor (2014). 
É importante deixar claro que as referências e explicações feitas aqui são relativas diretamente aos elementos astrológicos e não aos indivíduos especificamente. Os indivíduos absorvem as características e qualidades dos elementos, contudo a astrologia é complexa e há outros aspectos da mesma que tem influência sobre o indivíduo, como o signo solar, a posição dos planetas e luminares, os aspectos entre esses planetas etc. bem como a cultura e a história do mesmo.

\subsection{Método empírico}

A pesquisa empírica do presente estudo é qualitativa e quantitativa (DENCKER, 1998; MARCONI; LAKATOS, 2002; MOESCH, 2002; VEAL, 2011). Qualitativa porque ela propõe um estudo de perfis de turistas, onde o que será analisado são as informações referentes às suas características. Quantitativa porque é apresentada uma análise estatística de quantas pessoas responderam a questão de acordo com sua personalidade de fato. A questão aplicada foi de hierarquia, onde os entrevistados hierarquizavam as respostas disponíveis entre 1 e 4 , sendo 1 para a opção com a qual o entrevistado mais se identificava e 4 para a opção com a qual ele tinha menos afinidade. Para a sondagem da pesquisa foi escolhida a opção eletrônica, via rede social e e-mail, onde a questão foi respondida pelos entrevistados e enviadas novamente ao pesquisador (VEAL, 2011).

Este método foi escolhido porque ele se adequa ao objetivo da pesquisa: Determinar a média de pessoas que se identificam com seus elementos astrológicos dominantes, ou seja, se elas estão cientes ou não da influência dos mesmos sobre sua personalidade e seu tipo predominante de percepção.

Esta metodologia foi estabelecida com o intuito de cumprir com os objetivos propostos, minimizando as possíveis e variadas interpretações em relação ao perfil do consumidor turista. Por isso foram selecionados colaboradores aleatoriamente através de rede social na internet. Outro critério utilizado para a escolha dos colaboradores da pesquisa foi o fato de eles não possuírem conhecimento sobre astrologia, para que as respostas não fossem direcionadas. A identidade das pessoas que responderam ao questionário foi omitida, já que com o acesso ao mapa astrológico conteúdos pessoais da personalidade da pessoa podem ser visualizados. Por isso foram utilizadas somente as iniciais de seus nomes para a identificação na elaboração da Tabela 1. 
O questionário da pesquisa foi aplicado no período de 21 de junho de 2014 a 25 de junho de 2014, nestas datas foram enviados 48 questionários via rede social e e-mail. Este número foi escolhido para que se obtivesse uma amostra - não probabilística - razoável de colaboradores, ao mesmo tempo em que se utilizou um cálculo base relativo à estrutura do mapa astrológico - casas, signos e elementos -, onde são 12 casas e 12 signos e quatro elementos. Estes números foram multiplicados para resultar no número da amostra: 48. 32 pessoas (18 mulheres e 14 homens) responderam ao questionário entre os dias 21 de junho de 2014 e 01 de julho de 2014.

Posteriormente foi feita a identificação dos entrevistados onde os dados relevantes para a pesquisa foram a data, o horário e o local de nascimento, para que fosse possível a confecção do mapa astrológico de cada um. A confecção dos mapas astrológicos foi realizada através do site Sadhana Informática de programas profissionais de astrologia e o software utilizado para tal atividade foi o Vega Plus online.

Um questionário foi elaborado com uma pergunta contendo quatro opções de resposta - cada resposta relacionada a um elemento astrológico e baseada nos conceitos dos autores Arroyo (1972, 1989), Freeman (1981) e Hamaker-Zondag (1989). A justificativa para o questionário ter sido elaborado desta maneira é a de que a questão está relacionada ao tipo de influência que o elemento tem sobre a pessoa - a qual corresponde ao tipo de energia, consciência e percepção geral do indivíduo -, por isso na questão encontram-se as palavras 'características' e 'perfil'. Então a hierarquização das respostas realizada pelo entrevistado corresponderá ou não aos elementos dominantes do mesmo. É importante destacar que os elementos astrológicos não são mencionados no questionário, somente são mencionadas suas características correspondentes.

A metodologia da pesquisa se apresenta na seguinte sequência: (1) Elaboração do questionário; (2) Determinação do perfil e do número de consumidores turistas entrevistados; (3) Identificação dos entrevistados e confecção do mapa astrológico de cada um; (4) Aplicação do questionário; (5) Cálculo, com base nos mapas natais, dos elementos astrológicos dominantes e análise das respostas do questionário; (6) Correlação da hierarquia das respostas com os elementos astrológicos dominantes de cada entrevistado; (7) Contabilização das respostas 1 e 2, as quais são consideradas relacionadas aos dois elementos astrológicos dominantes. 
Houve alguns obstáculos no momento da aplicação do questionário, como falta de entendimento, por parte dos entrevistados, no momento de hierarquizar as respostas; alguns colaboradores ficaram em dúvida no momento de responder e por este motivo alguns repetiram números na hora de hierarquizar; e problemas para alcançar o número elegido para a amostra, pelo fato de as outras 16 pessoas não terem respondido o questionário. Por outro lado, a possibilidade de envio dos questionários pela internet facilitou a coleta das respostas e também a interpretação, por ser mais prático para a análise, a qual é apresentada na próxima seção.

\section{Resultados}

O objetivo desta análise é descobrir se as pessoas estão cientes ou não de seus elementos astrológicos dominantes e que os mesmos podem influenciar na personalidade e no modo de perceber do indivíduo. A partir das respostas do questionário aplicado em 32 pessoas foi possível obter dois tipos diferentes de resultados estatísticos e explicações para os mesmos com referência no material bibliográfico utilizado para escrever este artigo e aplicar a pesquisa.

Para analisar as respostas do questionário aplicado, foi elaborada a Tabela 1 onde constam: (1) Os entrevistados, identificados pelas letras iniciais de seus nomes, encontrados na primeira linha da tabela; (2) na coluna principal esquerda, os elementos astrológicos - Fogo, Terra, Ar e Água - coloridos com suas respectivas cores (vermelho, verde, azul e lilás) e, nas colunas ao lado direito da coluna principal, as respostas hierarquizadas - de 1 a 4 - do questionário em relação a estes elementos astrológicos, correspondentes aos entrevistados, encontrados na primeira linha; (3) os dois elementos astrológicos dominantes do mapa natal de cada pessoa, coloridos com as mesmas cores relativas aos elementos astrológicos encontrados na coluna principal esquerda, encontrados nas sétima e oitava linhas intituladas "Elementos dominantes dos entrevistados segundo mapa natal"; e (4) as análises elaboradas a partir das respostas 1 e 2 e 1 ou 2 dos entrevistados em relação aos seus elementos dominantes correspondentes, onde $\mathrm{x}$ indica acerto, no caso de a pessoa ter acertado seus dois elementos dominantes e no caso de a pessoa ter acertado um de seus dois elementos dominantes - estas informações, na tabela, se encontram a partir das linhas intituladas "Respostas 1 e 2" e "Respostas 1 ou 2". 
Para as respostas 1 e 2 elegidas repetidamente, no momento da análise relativa as respostas 2 correspondentes aos elementos dominantes, foi considerada tanto a resposta 1 quanto a resposta 2.

$\mathrm{Na}$ análise dos resultados foi feita a correlação entre as respostas 1 e/ou 2 - indicadas na questão da pesquisa pelos entrevistados - e os dois elementos astrológicos dominantes - os quais possuem maior pontuação no mapa natal, de acordo com o cálculo mostrado no capítulo 3, presente no subitem 3.1.3. Elementos astrológicos - de cada entrevistado.

Os critérios para acerto das respostas foram os seguintes:

1. Respostas 1 e 2 correspondentes aos elementos dominantes: Se a opção elegida como número 1 e a opção elegida como número 2, dentre as quatro opções de perfil, correspondem aos dois elementos dominantes da pessoa. Por exemplo: o entrevistado "AA" elegeu 1 para a primeira opção da questão e 2 para a última opção. A primeira opção da questão corresponde ao elemento Fogo e a última opção corresponde ao elemento Água. Fogo e Água são os elementos dominantes de "AA", portanto "AA" acertou a questão.

2. Respostas 1 ou 2 correspondentes aos elementos dominantes: Se a opção elegida como número 1 ou como número 2 , dentre as quatro opções de perfil, corresponde a um dos dois elementos dominantes da pessoa. Por exemplo: o entrevistado "VG" elegeu 2 para a segunda opção da questão. A segunda opção da questão corresponde ao elemento Terra. Terra é um dos elementos dominantes de "VG", portanto "VG" acertou a questão.

O fato de uma pessoa eleger o número 2 para uma opção que corresponda a um de seus dois elementos dominantes e não eleger o número 1 para outra opção que não corresponda a um de seus elementos dominantes pode ser aceito, pois não se pode descartar o fato de ela ter se identificado com um de seus dois elementos dominantes, mesmo que ele tenha sido marcado hierarquicamente como segunda opção. 
Tabela 1 - Análise das respostas referentes aos elementos dominantes dos entrevistados

\begin{tabular}{|c|c|c|c|c|c|c|c|c|c|c|c|c|c|c|c|c|c|c|c|c|c|c|c|c|c|c|c|c|c|c|c|c|}
\hline Entrevistados & AMP & $\mathrm{VG}$ & DV & RT & LS & $\mathrm{RF}$ & $\mathrm{AP}$ & $\mathrm{ACF}$ & $\mathrm{CV}$ & $\mathrm{JM}$ & $\mathrm{CB}$ & ES & $\mathrm{AT}$ & $\mathrm{DF}$ & IS & LB & $\mathrm{HF}$ & $\mathrm{RN}$ & IA & $\mathrm{AM}$ & DS & AJ & PM & EA & PG & $\mathrm{LC}$ & LFM & $\mathrm{LM}$ & CL & TS & AA & JÁ \\
\hline \multicolumn{33}{|c|}{ Respostas da pesquisa } \\
\hline Fogo & 1 & 3 & 1 & 1 & 3 & 2 & 2 & 3 & 1 & 2 & 2 & 1 & 2 & 3 & 2 & 2 & 4 & 1 & 1 & 1 & 2 & 1 & 1 & 3 & 4 & 3 & 4 & 2 & 4 & 2 & 1 & 2 \\
\hline Terra & 2 & 2 & 4 & 4 & 4 & 4 & 1 & 4 & 2 & 2 & 1 & 4 & 1 & 3 & 3 & 3 & 3 & 4 & 4 & 3 & 1 & 1 & 3 & 4 & 4 & 4 & 1 & 1 & 2 & 1 & 3 & 4 \\
\hline Ar & 3 & 4 & 3 & 3 & 2 & 3 & 3 & 2 & 2 & 1 & 1 & 2 & 2 & 1 & 4 & 4 & 2 & 3 & 3 & 2 & 2 & 2 & 2 & 2 & 2 & 1 & 3 & 2 & 3 & 1 & 4 & 3 \\
\hline Água & 4 & 1 & 2 & 2 & 1 & 1 & 2 & 1 & 1 & 2 & 2 & 3 & 1 & 2 & 1 & 1 & 1 & 2 & 2 & 2 & 2 & 2 & 4 & 1 & 1 & 2 & 2 & 1 & 1 & 2 & 2 & 1 \\
\hline \multirow{2}{*}{\multicolumn{33}{|c|}{$\begin{array}{l}\text { Elementos } \\
\text { dominantes dos } \\
\text { entrevistados segundo } \\
\text { mapa natal }\end{array}$}} \\
\hline & & & & & & & & & & & & & & & & & & & & & & & & & & & & & & & & \\
\hline Respostas 1 e 2 & $\mathrm{x}$ & & & & & & & & & & & & $\mathrm{x}$ & & & $\mathrm{x}$ & & $\mathrm{x}$ & $\mathrm{x}$ & $\mathrm{x}$ & $\mathrm{x}$ & $\mathrm{x}$ & & $\mathrm{x}$ & & $\mathrm{x}$ & & $\mathrm{x}$ & & $\mathrm{x}$ & $\mathrm{x}$ & $\mathrm{x}$ \\
\hline Respostas 1 ou 2 & $\mathrm{x}$ & $\mathrm{x}$ & & $\mathrm{x}$ & $\mathrm{x}$ & & $\mathrm{x}$ & $\mathrm{x}$ & $\mathrm{x}$ & $\mathrm{x}$ & $\mathrm{x}$ & $\mathrm{x}$ & $\mathrm{x}$ & $\mathrm{x}$ & $\mathrm{x}$ & $\mathrm{x}$ & $\mathrm{x}$ & $\mathrm{x}$ & $\mathrm{x}$ & $\mathrm{x}$ & $\mathrm{x}$ & $\mathrm{x}$ & $\mathrm{x}$ & $\mathrm{x}$ & $\mathrm{x}$ & $\mathrm{x}$ & $\mathrm{x}$ & $\mathrm{x}$ & $\mathrm{x}$ & $\mathrm{x}$ & $\mathrm{x}$ & $\mathrm{x}$ \\
\hline
\end{tabular}


Como dito anteriormente, algumas pessoas estão conscientes de seu eu interior e outras nem tanto. As influências externas podem confundir o indivíduo em relação ao conhecimento que ele tem ou poderia ter de si mesmo, ou inclusive limitar a sua expressão original (RUDHYAR, 1989). A consideração relevante à qual foi possível chegar com esta análise mesmo sendo a amostra limitada - é a de que há um número considerável de pessoas que se identificam com o seu self. Se formos partir da segunda análise, 30 de 32 pessoas têm ciência de sua percepção perante a vida. E esta é a proposta do elemento astrológico, ser o primeiro contato consciente do indivíduo em relação ao tipo de energia predominante que o habita (HAMAKER-ZONDAG, 1989). A seguir serão apresentados os acertos (e ausência deles) dos entrevistados relativos aos seus elementos dominantes.

\subsection{Respostas 1 e 2 correspondentes aos elementos dominantes}

Como mostra a Tabela 1, os entrevistados "AMP" e "DS" se identificam com seus dois elementos dominantes Fogo e Terra e possuem características que misturam dinamismo e estabilidade, espontaneidade e praticidade, impulsividade e perseverança de acordo com as respostas do questionário; assim como os entrevistados "AT", "AJ" e "LM" se identificam com os elementos Terra e Água, onde mesclam visão realista e imaginação, sensibilidade de emoções e determinação; os entrevistados "LB", "RN", "IA", "AA" e "JA" se identificam com os elementos Fogo e Água e possuem um perfil que mistura intuição e sentimento, ímpeto de explorar lugares e as próprias emoções; o entrevistado "AM" se identifica com os elementos Fogo e Ar, onde tanto dinamismo e impulsividade, quanto racionalidade e sociabilidade são características presentes; os entrevistados "EA" e "LC" se identificam com os elementos Ar e Água e possuem características que se misturam entre racionalidade, flexibilidade, vontade de se relacionar e se comunicar e sensibilidade e profundidade de sentimentos; e assim como o entrevistado "TS" se identifica com os elementos Terra e Ar, nos quais experimenta a estabilidade e praticidade da Terra e a flexibilidade e racionalidade do Ar.

\subsection{Respostas 1 ou 2 correspondentes aos elementos dominantes}

A pesquisa mostra que 16 pessoas das 32 que responderam ao questionário, se identificam somente com um de seus dois elementos dominantes. Conforme mostra a Tabela 1, os entrevistados "RT", “LS”, “AP”, “ACF”, “IS”, "HF” e "LFM” marcaram 1 para um de seus dois elementos dominantes; os entrevistados "VG", "CB", "ES", "DF", "PM", "PG” e "CL” marcaram 2 para um de seus dois elementos dominantes; os entrevistados "CV" e "JM" marcaram 2 para seus dois elementos 
dominantes. O entrevistado "RT" se identificou somente com o elemento Fogo; os entrevistados "VG", "LFM" e "CL" se identificaram somente com o elemento Terra; os entrevistados "ES", "PM" e "PG" se identificaram somente com o elemento Ar; os entrevistados "LS", "AP", "ACF", "CB", "DF", "IS" e "HF" se identificaram somente com o elemento Água; e os entrevistados "CV" e "JM" se identificaram de modo secundário com seus dois elementos dominantes.

\subsection{Respostas onde não foram marcados 1 e/ou 2 para elementos dominantes}

Duas pessoas das 32 que responderam aos questionários não marcaram 1 e/ou 2 para as opções que correspondiam aos seus elementos dominantes segundo seus mapas astrológicos. Este resultado nulo pode dever-se ao fato de o Sol, a Lua ou o Ascendente destas pessoas estarem localizados em signo e/ou casa astrológica de elemento diferente dos elementos dominantes expressos através do cálculo de elementos astrológicos dominantes. Isto porque o Sol, a Lua e o Ascendente exercem uma influência muito importante e grande sobre o indivíduo (ARROYO, 1987, 1989; BANZHAF; HAEBLER, 1994; FREEMAN, 1981; HAMAKER-ZONDAG, 1989; LIMA, 1998; LUNDSTED, 1989; RUDHYAR, 1972, 1989). No estudo em questão, o entrevistado "DV" possui Lua e Ascendente em signos de Fogo ("DV" marcou 1 para o elemento Fogo); e o entrevistado "RF" possui Sol e Lua em signos de Água ("RF" marcou 1 para o elemento Água). É preciso ter flexibilidade no momento da interpretação do perfil de uma pessoa e, principalmente, no momento da escolha de atividades turísticas. Por isso também a necessidade de um aprofundamento desta pesquisa, onde é possível obter informações mais detalhadas.

A análise da pesquisa trouxe o seguinte resultado: $47 \%$ (14) das 32 pessoas que responderam à questão da pesquisa estão totalmente cientes de seus dois elementos dominantes. 94\% (30) das 32 pessoas estão cientes ao menos de um de seus dois elementos dominantes. Isto leva-nos a considerar o fato de que é possível incluir a astrologia para ajudar a determinar o perfil do turista. A astrologia pode ser um colaborador no momento do turista escolher destinos e atividades turísticas que tenham a ver com o seu perfil e mais que isso, que possam ajudar no seu autoconhecimento.

\section{Conclusão}

Como principais conclusões deste artigo destaca-se a ligação entre astrologia e turismo como instrumento de análise do perfil do turista, na medida em que os resultados indicam, por exemplo, que turistas com perfil Terra e Água determinantes demonstram características de 
gostos relacionados à beleza (ligada aos cinco sentidos), aos estímulos sensoriais, à atividades gastronômicas, bem como à atividades ligadas à arte e que possibilitem uma profunda conexão com o divino. Ainda que a literatura do turismo não traga elementos que possam se verificar sob a luz de outros processos investigativos, por outro lado, autores específicos da astrologia permitem estabelecer gostos e preferências que poderão auxiliar na construção do conhecimento acerca destas relações.

Os autores da astrologia mostram elementos que podem ajudar na identificação do perfil turístico e que este possa estar atrelado ao perfil de consumo pela congruência estabelecida através da interpretação do mapa astrológico.

A questão utilizada para este trabalho pode colaborar com a pesquisa no momento em que ela evita confundir o indivíduo, na hora de responder, com perguntas relacionadas à sua personalidade e às atividades turísticas com as quais ele se identifica, ao mesmo tempo. Pois não necessariamente uma pessoa de elemento Fogo praticará atividades de aventura, já que ela pode ter limitações físicas ou psicológicas, mesmo assim isto não impede que a percepção dela seja baseada no dinamismo, na expansividade e na impulsividade. Isto acontece com todos os outros elementos astrológicos.

Por esse motivo esta pesquisa necessita de uma continuação para que seja possível uma maior exploração e compreensão do assunto, bem como seus limites e perspectivas, e principalmente, tentar descobrir se os turistas geralmente preferem ou praticam atividades correspondentes aos seus elementos dominantes. Esta questão se mostrou crucial ao estabelecer a relação entre o referencial teórico e a análise dos dados.

Métodos de pesquisa como conversação e gravação ou questionários onde o entrevistado possa discorrer livremente sobre os assuntos viagem e personalidade podem ser mais interessantes para uma próxima etapa da pesquisa e colaborarão de forma mais assertiva para que se tenha acesso a um maior número de informações, o que dá mais facilidade no momento de interpretar as respostas obtidas.

A astrologia é mais uma disciplina ou conhecimento que pode ser incluído nos estudos do turismo, já que o mesmo é um campo multidisciplinar e interdisciplinar vasto, o qual necessita da visão holística para funcionar bem. É esta visão e a prática da mesma que farão com que as várias disciplinas se interliguem e trabalhem juntas - com a percepção de que uma não existe sem a outra - para um melhor direcionamento e execução do turismo. 
O intuito deste artigo foi dar início ao trabalho relacionando o campo da astrologia como ciência e turismo como atividade que propõe o deslocamento de pessoas por seus gostos e preferências, o qual resultará numa série de pesquisas que busca refinar a compreensão destas relações e, fundamentalmente, ajudar a encontrar na viagem realizações com base no próprio perfil do turista.

\section{Referências}

ARROYO, S. Astrologia, psicologia e os quatro elementos. São Paulo: Pensamento, 1987. . Normas práticas para a interpretação do mapa astral. São Paulo: Pensamento, 1989.

ATELJEVIC, I. Transmodern critical tourism studies: a call for hope and transformation. Turismo em análise, vol. 22, n. 3, p. 497-515, 2011.

BACAL, S. Lazer e o universo dos possíveis. São Paulo: Aleph, 2003.

BALOGLU, S.; MCCLEARY, K. W. A model of destination image formation. Annals of tourism research, vol. 26, n. 4, p. 868-897, 1999.

BANZHAF, H e HAEBLER, A. Palavras-chave da astrologia. São Paulo: Pensamento, 1994.

BAUDRILLARD, J. A sociedade de consumo. Ed. 70. Lisboa: 1991.

BEERLI, A.; MARTÍN, J. D. Tourists' characteristics and the perceived image of tour destinations: a quantitative analysis: a case study of Lanzarote, Spain. Tourism management, vol. 25, p. 623-636, 2004.

BENI, M. C. Análise estrutural do turismo. Ed. 13. São Paulo: Senac, 2008.

BIGNÉ, J. E.; SÁNCHEZ, M. I.; SÁNCHEZ, J. Tourism image, evaluation variables and after purchase behavior: Inter-relationship. Tourism management, vol. 22, n. 6, p. 607-616, 2001.

BOSQUE, I. R.; MARTÍN, H. S. Tourist satisfaction: a cognitive-affective model. Annals of tourism research, vol. 35, n. 2, p. 551-573, 2008.

CHAUI, M. Convite à filosofia. Ed. 14. São Paulo: Ática, 2010.

$\mathrm{CHON}, \mathrm{K}$. S. The role of destination image in tourism: an extension. The tourist review. The journal of the international association of scientific experts in tourism, vol. 43, n. 1, p. 2-8, 1992.

COHEN, E. Toward a sociology of international tourism. Social Research, vol. 39, n. 1, p. 164-182, 1972.

COSHALL, J. T. "Measurement of tourists" images: the repertory grid approach. Journal of travel research, vol. 39, n. 1, p. 85-89, 2000.

DENCKER, A. F. M. Metodologia de pesquisa em turismo. São Paulo: Futura, 1998.

DOLNICAR, S.; HUYBERS, T. Different tourists - different perceptions of different places: accounting for tourists' perceptual heterogeneity in destination image measurement. Tourism analysis, vol. 12, p. 447-461, 2007.

ECHTNER, C. M.; RITCHIE, J. R. The meaning and measurement of destination image. The journal of tourism studies, vol. 2, n. 2, p. 2-12, 1991.

ELGIN, D. Global consciousness change: Indicators of an emerging paradigm. San Anselmo:

Millennium Project, 1997. 
FONSECA FILHO, A. S. Educação e turismo: Reflexões para elaboração de uma educação turística. Revista brasileira de pesquisa em turismo, vol. 1, n. 1, p. 5-33, 2007.

FREEMAN, M. Como interpretar seu mapa astral. Rio de Janeiro: Nova Fronteira, 1981.

FREUD, S. O Ego e o Id. Edição Standard brasileira das obras psicológicas completas de Sigmund Freud, vol. XIX. Rio de Janeiro: Imago, 1974.

GALLARZA, M. G.; CALDERÓN, H. G.; GIL, I. S. Destination image: Towards a conceptual framework. Annals of tourism research, vol. 29, n.1, p. 56-78, 2002.

GÂNDARA, J. M. G.; GIMENES, M. H. S. G.; MASCARENHAS, R. G. Reflexões sobre o turismo gastronômico na perspectiva da sociedade dos sonhos. In PANOSSONETTO, A. e ANSARAH, M. G. Segmentação do mercado turístico: estudos, produtos e perspectivas. Barueri: Manole, 2009.

GUITIÉRREZ, H. S. M. Estudio de la imagen de destino turístico y el proceso global de satisfacción: adopción de un enfoque integrador. 2005. Tese (Departamento de Administración de Empresas) Universidad de Cantabria, Santander (ES), 2005.

GULMEZ, M; KITAPCI, O; DORTYOL, I. The effect of astrology on young customer behaviors. Studies in business and economics, vol. 6, n. 3, p. 97-109, 2011.

HAMAKER-ZONDAG, K. Os quatro elementos e os caminhos da energia. Rio de Janeiro: Nova Fronteira, 1989.

HERZBERG, E. Managers seek starry advice. International management, vol. 20, p. 36-8, 1973.

INGLEHART, R. The silent revolution: changing values and political styles among western publics. Princeton NJ: Princeton University Press, 1977.

INGLEHART, R.; NORRIS, P. Sacred and secular: Religion and politics worldwide. New York: Cambridge University Press, 2004.

JENKINS, O. H. Understanding and measuring tourist destination images. International journal of tourism research, vol. 1, n. 1, p. 1-15, 1999.

KRIPPENDORF, J. Sociologia do turismo: para uma nova compreensão do lazer e das viagens. Ed. 3. São Paulo: Aleph, 2009.

LEMOS, L. O valor turístico na economia da sustentabilidade. São Paulo: Aleph, 2005.

LIMA, J. C. P. A mandala do amor: Astrologia, meditação e cura. São Paulo: Ground, 1998.

LUNDSTED, B. Compreensão astrológica da personalidade. São Paulo: Ágora, 1989.

MANOSSO, F. C.; GÂNDARA, J. M. G.; SOUZA, T. A.; BÓGEA, V. A gestão das emoções dos hóspedes. Revista brasileira de pesquisa em turismo, vol. 6, n. 3, p. 357-374, 2012.

MARCONI, M. A. e LAKATOS, E. M. Técnicas de pesquisa. São Paulo: Atlas, 2002.

MELO, E. S. O. Aprofundando o olhar do turista: Considerações acerca de suas determinantes sociais. Revista brasileira de pesquisa em turismo, vol. 3, n. 2, p. 71-94, 2009.

MILMAN, A.; PIZAM, A. The Role of awareness and familiarity with a destination: The Central Florida case. Journal of travel research, vol. 33, n. 3, p. 21-27, 1995.

MITCHELL, V. Using astrology in market segmentation. Management decision, vol. 33, n. 1, p. 4857, 1995.

MITCHELL, V.; HAGGETT, S. Sun-sign astrology in market segmentation: An empirical investigation. Journal of consumer marketing, vol. 14, n. 2, p. 113-131, 1997.

MOESCH, M. A produção do saber turístico. Ed. 2. São Paulo: Contexto, 2002. 
MORIN, E. Cultura de massas no século XX: O espírito do tempo. Rio de Janeiro: Forense Universitária, 1975.

PINTO, R. A formação das imagens no turismo: Itinerário teórico de proposta de um modelo operacional. Turismo em análise, vol. 23, n. 3, p. 552-574, 2012.

RUDHYAR, D. As casas astrológicas: O espectro da experiência individual. São Paulo: Pensamento, 1972.

. Astrologia da personalidade: Uma reformulação de conceitos e ideais astrológicos em termos de psicologia e filosofia contemporâneas. São Paulo: Pensamento, 1989.

SADHANA INFORMÁTICA. Programas profissionais de astrologia. Disponível em: <http://www.sadhana.com.br>. Acesso em 27 jun. 2014.

SWARBROOKE, J. e HORNER, S. O Comportamento do consumidor no turismo. São Paulo: Aleph, 2002.

TAPACHAI, N.; WARYSZAK, R. An examination of the role of beneficial image in tourist destination selection. Journal of travel research, vol. 39, n. 1, p. 37-44, 2000.

TONINI, H. Economia da experiência: O consumo de emoções na "Região Uva e Vinho". Revista brasileira de pesquisa em turismo, vol. 3, n. 1, p. 90-107, 2009.

URRY, J. O Olhar do turista: Lazer e viagens nas sociedades contemporâneas. São Paulo: Sesc, 1996.

VEAL, A. J. Metodologia de pesquisa em lazer e turismo. São Paulo: Aleph, 2011.

VIEIRA FILHO, H. Psicoterapia holística. Disponível em:

<http://www.psicanalista.com.br/component/content/article/29-terapia-holistica/72-consciente-

inconsciente>. Acesso em 22 jun. 2014.

\section{Recebido em: 26/05/2015 (1 ${ }^{\mathrm{a}}$ versão $)$}

Aprovado em: 22/11/2015

\section{Apêndice - Questionário Perfil Astrológico do Turista}

Quais das características abaixo têm mais a ver com você? Com quais você mais se identifica? Estabeleça uma hierarquia de 1 a 4 (1,2, 3 e 4), sendo 1 a opção de características que mais tem a ver com o seu perfil e 4 a opção de características que menos tem a ver com o seu perfil.

( ) Futuro, possibilidades, descoberta e dinamismo têm um papel importante no seu mundo. Espontaneidade, impulsividade e entusiasmo fazem parte de você. Você percebe intuitivamente como tudo é ou deveria ser.

( ) Percebe principalmente o que é palpável e por meio dos sentidos físicos. Realista, prático, estável e perseverante. Precisa de segurança material. É através da sensação que você percebe a vida.

( ) O mundo das ideias é imprescindível para você. Racionalidade, liberdade de pensamento, comunicação, sociabilidade e flexibilidade fazem parte de você. Percebe o mundo ao seu redor através do pensamento.

( ) Sensibilidade e imaginação fazem parte de você. É importante o sentimento despertado por uma pessoa, objeto ou situação. Costuma envolver-se profundamente em suas vivências, mesmo que possa não demonstrar. Percebe o mundo de forma sentimental. 